\title{
Effect of tow-drop gaps on the damage resistance and tolerance of Variable-Stiffness Panels
}

\author{
O. Falcóa ${ }^{a}$ C. S. Lopes ${ }^{\mathrm{b}, \mathrm{c}}$, J. A. Mayugo ${ }^{\mathrm{a}}$, N. Gascons ${ }^{\mathrm{a}}$, J. Renart ${ }^{\mathrm{a}}$ \\ ${ }^{a}$ AMADE, Department of Mechanical Engineering and Industrial Construction, Universitat de Girona, \\ Campus Montilivi s/n, 17071 Girona, Spain \\ ${ }^{b}$ IMDEA Materials: Madrid Institute for Advanced Studies of Materials, Getafe (Madrid), Spain. \\ ${ }^{c}$ INEGI: Instituto de Engenharia Mecânica e Gestao Industrial, Porto, Portugal.
}

\begin{abstract}
This paper presents an experimental study of the effects of tow-drop gaps in Variable Stiffness Panels under drop-weight impact events. Two different configurations, with and without ply-staggering, have been manufactured by Automated Fiber Placement and compared with their baseline counterpart without defects. For the study of damage resistance, three levels of low velocity impact energy are generated with a drop-weight tower. The damage area is analyzed by means of ultrasonic inspection. Results indicate that the influence of gap defects is only relevant under small impact energy values. However, in the case of damage tolerance, the residual compressive strength after impact does not present significant differences to that of conventional straight fiber laminates. This indicates that the strength reduction is driven mainly by the damage caused by the impact event rather than by the influence of manufacturing-induced defects.
\end{abstract}

Keywords:

Carbon fiber reinforced polymer; Defects; Variable-Stiffness Panels; Automated Fiber Placement

\section{Introduction}

Currently, most composite laminates for structural applications in aircraft programs are manufactured using only the traditional straight fibre configurations, which consist mainly of quasi-isotropic layups. As a consequence, neither the full advantage of the Automated Fiber

Email address: ja.mayugo@udg.edu (J. A. Mayugo) 
Placement technology (AFP), available since the 1990s, nor the novel laminate concepts are being used efficiently [1]. The increasing trend toward the development of lighter structures based on an optimized use of composites with Non-Conventional Layups (NCLs) is possible by tailoring the direction and placement of fiber laminates - also referred to as variable angle tow composites.

NCLs are defined as disperse stacking sequence laminates [2], or layups, produced by steering tows that follow curved paths. They are also called Variable Stiffness Panels (VSP) [3]. In the past, researchers have studied the advantages of these VSP over conventional laminates and VSP have been proven to be effective in enhancing the buckling and postbuckling response by in-plane load redistribution $[4,5,6]$. Also, VSP showed potential for lessening notch sensitivity and for reducing stress concentration effects [7, 8, 9, 10]. However, a better comprehension of the mechanical response, failure and damage mechanisms in VSP has prevented its extended application. In addition, due to the versatility and design complexity of VSP, the introduction of these advanced concepts will become feasible only if two major issues are considered. Firstly, by developing reliable design methodologies to predict the mechanical response from damage onset up to structural collapse. Secondly, by certifying VSP using high-level component tests in order to understand the process-induced defects.

Nowadays, there are efficient methodologies to design the optimal fiber orientation so as to maximize the structural efficiency of VSP $[11,12,13,14,15]$, accounting for the manufacturing defects as well $[16,17,18]$. These defects appear during the tow-steering process and are inherent to the AFP head mechanism [3]. The process-induced defects include local tow buckling or winkling and thickness change due to tow-drop gaps or overlaps. These defects become potential spots for the initiation of matrix cracking or even delaminations [19], and are key issues which need to be addressed to guarantee performance. Another crucial problem in VSP is related to fiber discontinuities. It is worth mentioning that a novel fiber placement technique called Continuous Tow Shearing (CTS) [20] has been developed to avoid most of the problems mentioned above. This technology relies on the shear deformation capability of dry tows. However, one of its drawbacks is the maximum variation of tow angle. 
Experimental tests are needed to evaluate the influence of the gap or overlap defects originated in the real AFP environment. A wide variety of failure and damage mechanisms appear in the NCLs as a result of design complexity and manufacturing process. In order to fully exploit the possibilities of NCLs and their use in composite structures, the effect of process-induced defects requires specific attention. In the past, researchers have studied the effect of converging gap defects [21, 22]. These studies demonstrated that the unnotched tension and compression tests showed significant reductions in strength due to the gaps. Whereas, open hole tension tests were unaffected by the presence of gaps. This was attributed to the hole effect dominating the gap effects. It also was demonstrated that the compression tests are more sensitive to the gap defects than the tension tests are. In addition, failure predictions depended on the gap locations and the number of gaps. Another author, Nicklaus [23], demonstrated that the presence of gaps produce higher fracture toughness values in the areas close to the hole.

Recently, Croft et al. [24] presented an experimental study quantifying the effect of the main manufacturing-induced single defects under tensile, compression and shear loading. Their work reveals that the in-plane shear strength decreased when there was towoverlapping along the perpendicular direction to the load. A further study on the influence of tow-drop gap defects, gap-coverage parameter and the staggering technique under in-plane tensile loading in VSP has been presented by the present authors (Falco et al. [25]). That work shows that the configurations where gaps are not covered and plies are not staggered present the most critical strength reduction as a consequence of the clustering of gaps. Large delaminations are initiated in the vicinity of the tow-drop defects, which are then followed by extensive matrix cracking and finally fiber failure. The present contribution deals with a similar sub-domain of VSP, but focuses on the damage resistance and damage tolerance to a drop-weight impact event.

Damage tolerance to low-velocity impacts is a key factor in the design of the majority of aircraft structures due to the low out-of-plane strength of the composites. Such impacts can happen during manufacturing, servicing or maintenance operations. Several experimental investigations have studied the damage response of dispersed laminates to low-velocity impact, and their improvement over conventional laminates [19, 26, 27]. The differences are 
related to the effects of bending stiffness, ply clustering and mismatch angle between the plies. It has been demonstrated that the dispersion of ply orientations through the whole [0 ० -90॰] range has beneficial effects in terms of impact resistance [28]. By reducing the mismatch angles between the adjacent layers, the response is improved in terms of smaller indentation, less damage dissipated energy, delaminations and higher residual strength. In addition, even for laminates with good stiffness properties, the clustering of plies can lead to large delaminations because there are less potential interfaces for delaminations, resulting in a lower damage resistance of the structure [29].

In VSP, all these aspects are combined in a more complex environment which includes process-induced defects. Additionally, mismatch angles appear not only between adjacent layers, but also within the plies, between adjacent shifted courses. Impact events in VSP is a relatively new field of research. Dang et al. [30] performed a numerical study on impact and Compression After Impact (CAI) using finite element analysis. Their results conclude that the main reason for the reduction in compressive strength is related to significant delamination. However, their numerical model only considers the effect of fiber steering, while process-induced defects were not considered. Rhead et al. [31] present the effect of tow gaps on the compression-after-impact strength of fiber-placed laminates. The results show that the position, width and depth of tow gaps have a significant effect on damage resistance i.e. the tow gaps close to the non-impacted surface can inhibit sublaminate buckling and growth of laminations. However, in the design of their specimens the shape of the tow gaps is continuous and the mismatch angle discontinuities between the courses were omitted. In reality, in the vicinity between two adjacent courses, small triangular fiber-free areas (gaps), are created in order to avoid overlapping. In addition, the proper nature of the course shifting method [3], creates fiber angle discontinuities.

In this work, the aspects mentioned above have been reproduced in a laminate which could be a representative subdomain of a real VSP. The main goal is to study the influence of gap defects on the damage resistance and on the compressive residual strength of three laminates under low velocity impacts. Also, the effect of the staggering technique, used to avoid the co-location of the gaps, has been analyzed. The staggering technique reduces the effect of ply clustering and produces a more uniform distribution of the process-induced 
defects. Both configurations, with and without staggered plies, have been compared with a traditional straight fiber laminate. All configurations analyzed present similar bending stiffness in order to avoid misinterpreting the results and reaching ambiguous conclusions.

\section{Specimen with tow-drop gaps: Design and manufacturing}

The test specimens for the experimental work reported in this paper have been designed to represent the ply discontinuities at the edges of adjacent courses in VSP configurations. Gap-coverage zones have been included in order to study the influence of the process-induced defects and the staggering technique, under drop-weight impact. Each specimen represents a sub-domain of a whole Variable Stiffness Panel at the boundary between the courses. The effects to be studied are very localized, this makes it possible to use relatively small specimens and to use straight-fiber laminates instead of curved trajectories. Some layers in the laminate have one portion with the fibers at $51^{\circ}$ and another at $39^{\circ}$, thus creating an angle discontinuity at the mid-length of the specimen. In order to avoid more complexity, these plies with angle discontinuity were balanced with plies at $-45^{\circ}$.

Two configurations with tow-drop defects and $0 \%$ gap-coverage where designed and tested under low-velocity impact. The configurations are described in Fig 1a. The difference between them is in the use of ply staggering. In the first case, the fiber-resin areas are colocated through-the-thickness. Whereas for the second case, the co-location of gaps is avoided by staggering the plies in relation to each other (see Fig 1b). The thickness variation caused by the pressing of gaps in adjacent layers resulting from the high pressure of the curing process is observed in Fig 1c.

The composite material used in this investigation is the HexPly AS4/8552 pre-impregnated CFRP in $6.35 \mathrm{~mm}\left(1 / 4 \mathrm{in}\right.$.) wide tows $\left(t_{\mathrm{w}}\right)$, with nominal ply thickness after curing of 0.18 $\mathrm{mm}$. The manufacturing process was done in the National Aerospace Laboratory-NLR (The Netherlands), with a Coriolis Fiber Placement Machine which lays courses of up to 8 tows at a time with a total width $\left(C_{\mathrm{w}}\right)$ of $50.8 \mathrm{~mm}$ per course. The mechanical properties of the material system are $E_{11}=138.0 \mathrm{GPa}, E_{22}=8.6 \mathrm{GPa}, G_{12}=4.9 \mathrm{GPa}$ and $\nu_{12}=0.35$. The tests are performed on flat rectangular plates of $150 \times 100 \mathrm{~mm}$. The stacking sequence analyzed is $\left[45 / 0 /-45 / 90 /\left(-45_{2} /(51 \mid 39)_{2}\right)_{2}\right]_{s}$, where the $0^{\circ}$ fiber orientation is aligned with the largest 

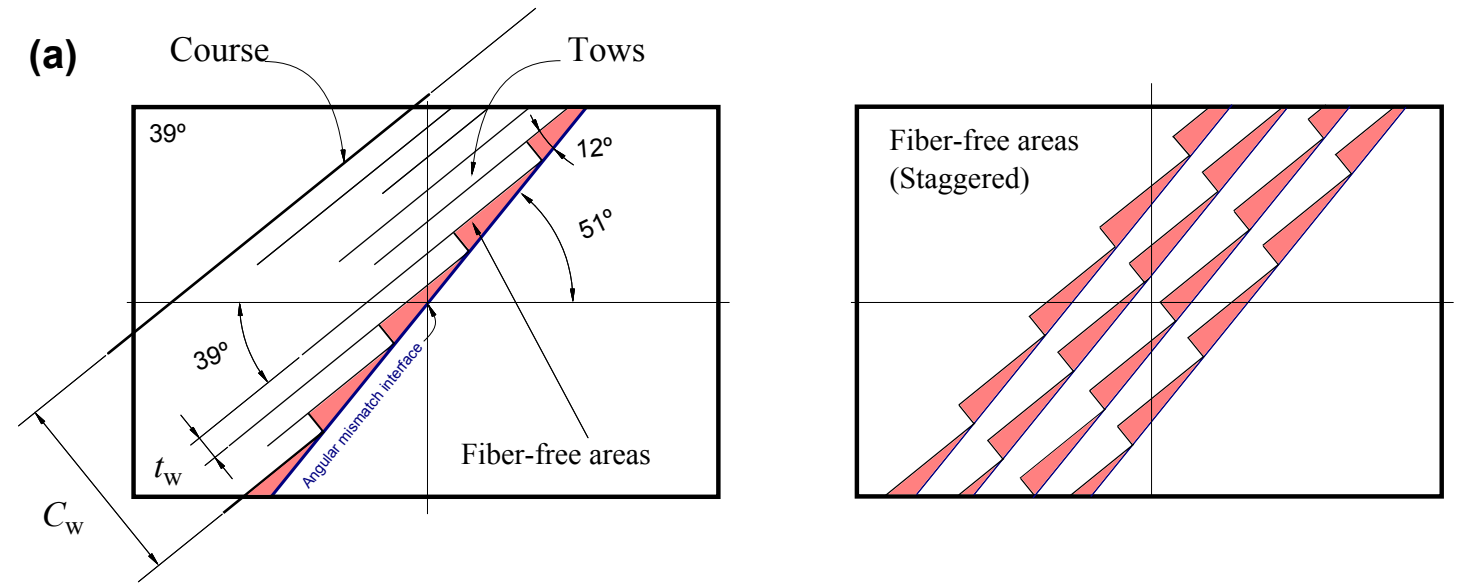

(b)

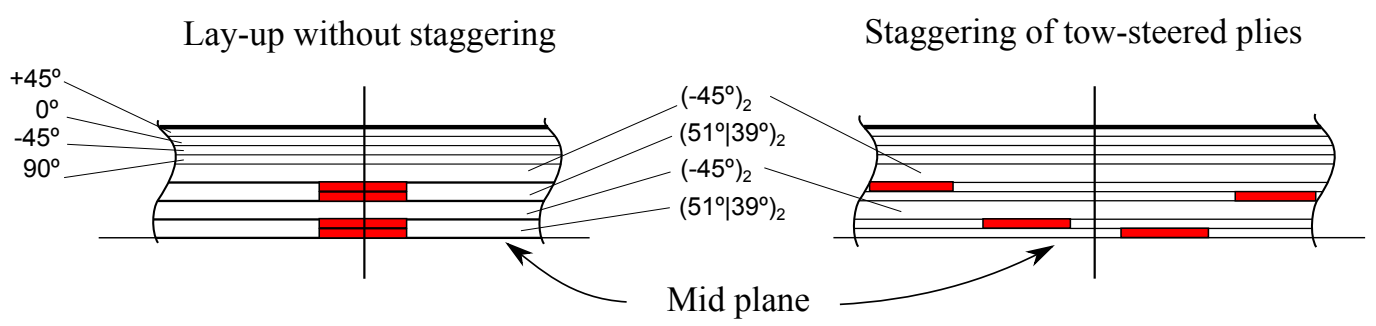

\section{Baseline}

(c)

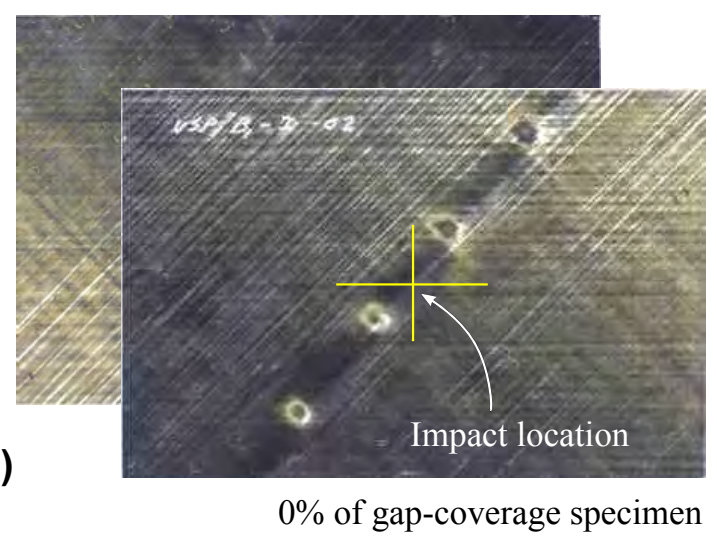

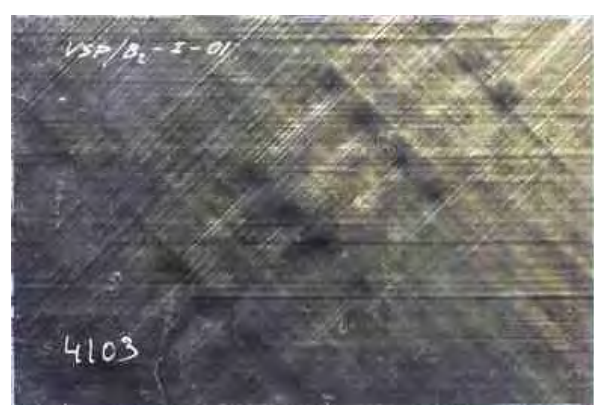

$0 \%$ of gap-coverage specimen with staggering

Figure 1: a) Specimen geometry: The discontinuity interface in the ply $\langle 51 \mid 39\rangle$ is represented using a blue line and resin rich areas have been filled. (b) Tow-drop gap defects ('no Staggering' and 'Staggering'). (c) Real specimen with and without staggering.

in-plane dimension. The design of the external plies was constrained to the conventional straight-fiber method to avoid gap defects in the outer layers of the laminate. All configurations present the same staking sequence (24 plies) with nominal laminate thickness of 4.32 mm. A baseline laminate with a staking sequence of $\left[45 / 0 /-45 / 90 /\left(-45_{2} / 45_{2}\right)_{2}\right]_{s}$ has also been analyzed and tested for comparative purposes. The baseline and the non-conventional 
laminates were designed to have similar global stiffness.

\section{Drop-weight impact and compression after impact tests}

The ASTM D7136 [32] standard establishes the method for measuring the damage resistance to a fiber-reinforced polymer matrix composite under a drop-weight impact. In this study, three impact energies $\left(E_{\mathrm{i}}\right)$ have been used: $15 \mathrm{~J}, 30 \mathrm{~J}$ and $45 \mathrm{~J}$. The impact mass $\left(M_{\mathrm{i}}\right)$ values, the velocity before the impact values $\left(V_{0}=\sqrt{2 E_{\mathrm{i}} / M_{\mathrm{i}}}\right)$ and the impact height values $\left(H_{\mathrm{i}}=E_{\mathrm{i}} /\left(M_{\mathrm{i}} g\right)\right)$ are summarized in Table 1 . For each impact energy and for each configuration, two specimens with gap defects have been tested. Additionally, two specimens with the baseline configuration are used to assess the non-impacted laminate strength.

Table 1: Impact energies, mass, velocities and drop weight heights.

\begin{tabular}{lrrr}
\hline & \multicolumn{3}{c}{ Impact energy $(\mathrm{J})$} \\
\cline { 2 - 4 } & 15 & 30 & 45 \\
\hline Impactor mass $M_{\mathrm{i}}(\mathrm{kg})$ & 5.0 & 5.0 & 5.0 \\
Initial velocity $V_{0}(\mathrm{~m} / \mathrm{s})$ & 2.5 & 3.5 & 4.2 \\
Impact height $H_{\mathrm{i}}(\mathrm{mm})$ & 306 & 612 & 917 \\
\hline
\end{tabular}

The impact tests were carried out in a Instron Ceast 9350 (Fractovis Plus, Italy) instrumented drop-weight tower, with a $16 \mathrm{~mm}$ diameter hemispherical impactor and an automatic anti-rebound impactor system. The unsupported area of the specimen during the impact is $125 \mathrm{~mm}$ by $75 \mathrm{~mm}$. The data recorded are the history of the impactor force, displacement and velocity. After the impact tests and a dent-depth measurement, all specimens were inspected with an Omni-Scan MX (Olympus NDT, USA) ultrasonic system to analyse the resulting delamination area. For the non-staggered specimens the impact location is controlled. For each energy level, one specimen was tested with the impact outside of the defect and the other impacted just inside of the fiber-free area. Conversely, this differentiation is not possible with the other configurations.

The Compression After Impact (CAI) tests were performed using a hydraulic MTS810 (Material Testing Systems, USA) testing machine of $250 \mathrm{kN}$ load-capacity and with 
an anti-buckling fixture support at the specimen edges, according to the ASTM D7137 [33]. The same standard is followed in determining the residual compression after impact strength $\sigma_{\mathrm{c}}$ of each specimen. The normalized residual compression strength after impact is calculated using the expression: $\sigma_{\mathrm{c}}=P_{\mathrm{r}} /\left(W \cdot t_{\mathrm{n}}\right)$, where $P_{\mathrm{r}}$ is the break failure load of the specimen of width $(W)$ and nominal thickness $\left(t_{\mathrm{n}}\right)$. In order to monitor the out-ofplane displacements, two displacement transducers are used during the CAI tests. However, for some specimens a more reliable technique, the Digital Image Correlation (DIC) system VIC $-3 D^{T M}$ Measurement System (Correlated Solutions, USA) is used. This technology allows out-of-plane displacement and strain fields for the whole surface to be monitored, as well as any possible eccentricities that might occur.

\section{Results and discussion}

In order to study the influence of tow-drops on damage resistance and damage tolerance, two different configurations with these defects are analyzed and compared with a conventional baseline laminate. Firstly, the results obtained with the impact test are presented. Here, the most relevant features of composite laminates under low velocity impact condition are: the delamination threshold loads, the peak loads, the evolution of the absorbed energies and the projected delamination areas as a result of the impact. Secondly, the residual compressive strengths obtained through CAI tests are analyzed.

\subsection{Low velocity impact test results}

The corresponding histories of the impact loads as a function of the contact time and of the impactor displacement for the three impact values of energy (15 J, $30 \mathrm{~J}$ and $45 \mathrm{~J}$ ) are shown in Fig 2. For the particular case of the laminate with no staggering, both impacted specimens are represented, because of the differences observed. For the specimens labelled 'no Staggering-side' the impact location is outside the defect zone, and for the specimens 'no Staggering-gap' the impact zone is just inside the fiber-free area. In the other configurations, only one specimen was selected because no significant differences were detected. These impact load evolutions make it possible to determine the delamination threshold load $F_{\mathrm{d}}$ and the peak load $F_{\mathrm{p}}$. On the one hand, the $F_{\mathrm{d}}$ can be identified as the first significant force 
drop in the load impact evolution. $F_{\mathrm{d}}$ represents the initial value at which a significant change in the stiffness properties is detected. Its value is also associated with the development of a first significant delamination [29]. After this point, the response is affected by a large variety of damage mechanisms - matrix cracking, fiber-matrix interface debonding, delamination and fiber breakage. On the other hand, the peak load $F_{\mathrm{p}}$ is the maximum force recorded during the impact process.

The threshold load $F_{\mathrm{d}}$ has similar values for impact energies of $15 \mathrm{~J}, 30 \mathrm{~J}$ and $45 \mathrm{~J}$. Excluding the tests labelled as 'no Staggering-gap', the delamination threshold load $F_{\mathrm{d}}$ for the all configurations analyzed had similar values. Therefore, this agrees with other experimental works [29] where the $F_{\mathrm{d}}$ value is independent of the impact energy. Note that the 'no Staggering-gap' tests were carried out on specimens impacted in the gap defect. For this configuration, a reduction of about $30 \%$ in $F_{\mathrm{d}}$ was observed for all impact energies.

The delamination threshold loads are on average $6.4 \mathrm{kN}, 6.1 \mathrm{kN}$ and $6.0 \mathrm{kN}$ for the configurations 'baseline', 'no Staggering' and 'staggering', respectively. The corresponding energy levels for these configurations are 6.2 J,6.1 J and 5.8 J. In comparison, in the cases when the impact occurs inside the fiber-free area, the average of the threshold load is 4.3 $\mathrm{kN}$, occurring at energy levels of $3.1 \mathrm{~J}$.

As expected, the peak load $F_{\mathrm{p}}$ and the total impact time increase by intensifying the impact energy. The value of $F_{\mathrm{p}}$ for the baseline and staggered configurations have similar values. For the configuration without staggering, a slight reduction of $F_{\mathrm{p}}$ of $6.8 \%, 11.2 \%$ and $8.7 \%$ is observed for impact energies $15 \mathrm{~J}, 30 \mathrm{~J}$ and $45 \mathrm{~J}$, respectively. This is probably as a result of different damage mechanisms depending on the co-location of the fiber-free areas.

The absorbed energy value represents how the impactor kinetic energy is transferred to the specimen by means of different failure mechanisms, mainly in the form of delaminations. The evolution of the absorbed energy for each tested laminate and its corresponding impact energy are shown in Fig 3.

The analyses of the dissipated energy shows very similar behavior between the configuration baseline and the configuration with staggered fiber-free areas. The non-staggered configuration shows a higher energy dissipation. This means that the clustered fiber freeareas (gap-defects) are more prone to damage. In addition, if the staggering technique is 

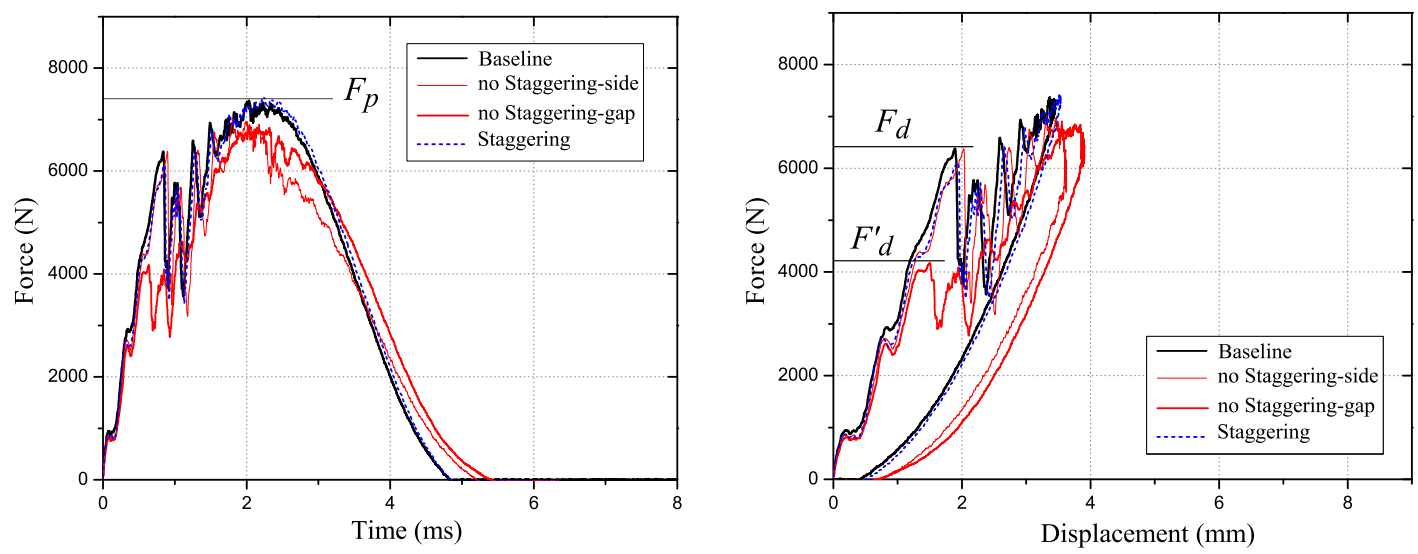

(a) Configurations tested at $15 \mathrm{~J}$ impact energy
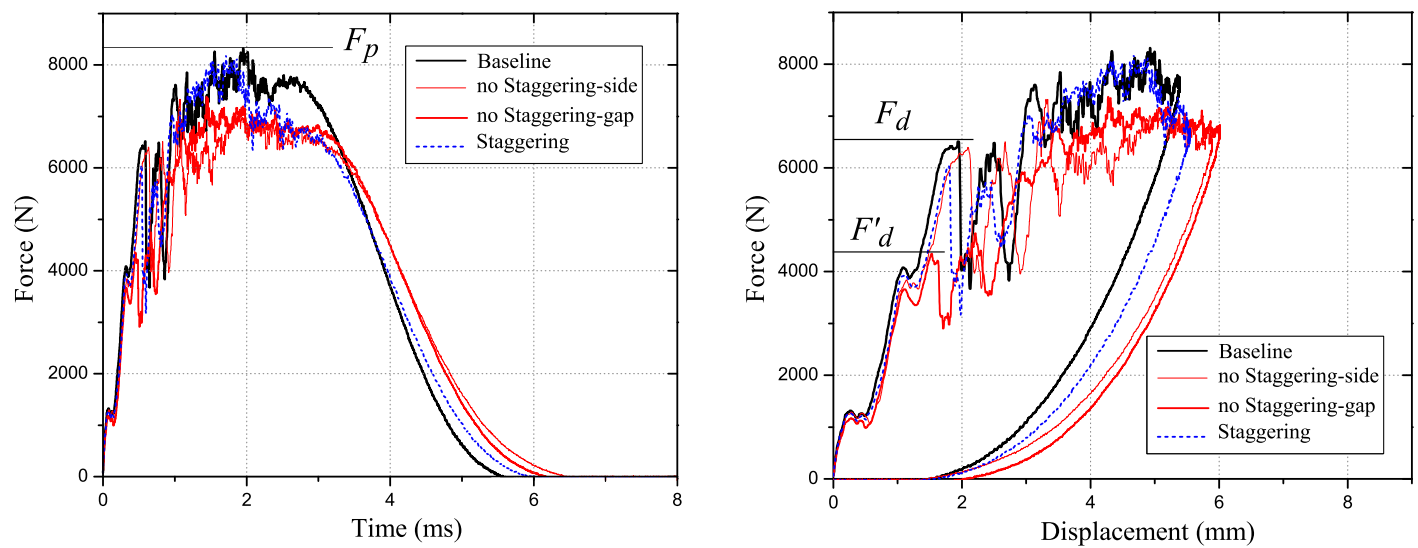

(b) Configurations tested at $30 \mathrm{~J}$ impact energy
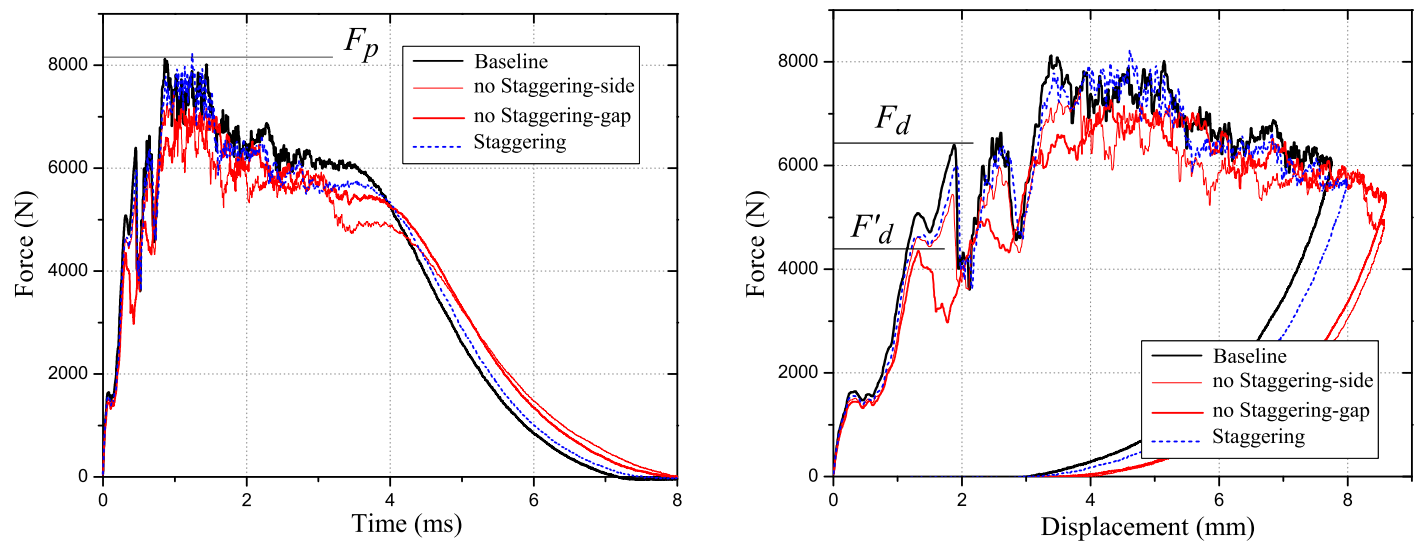

(c) Configurations tested at $45 \mathrm{~J}$ impact energy

Figure 2: Impact load evolution and in function of displacement for the configurations 'Baseline', 'no Staggering' and 'Staggering' tested at: (a) $15 \mathrm{~J}$, (b) $30 \mathrm{~J}$ and (c) $45 \mathrm{~J}$. The values $F_{\mathrm{p}}$ and $F_{\mathrm{d}}$ for the baseline configuration are marked for each impact energy by a horizontal line. 

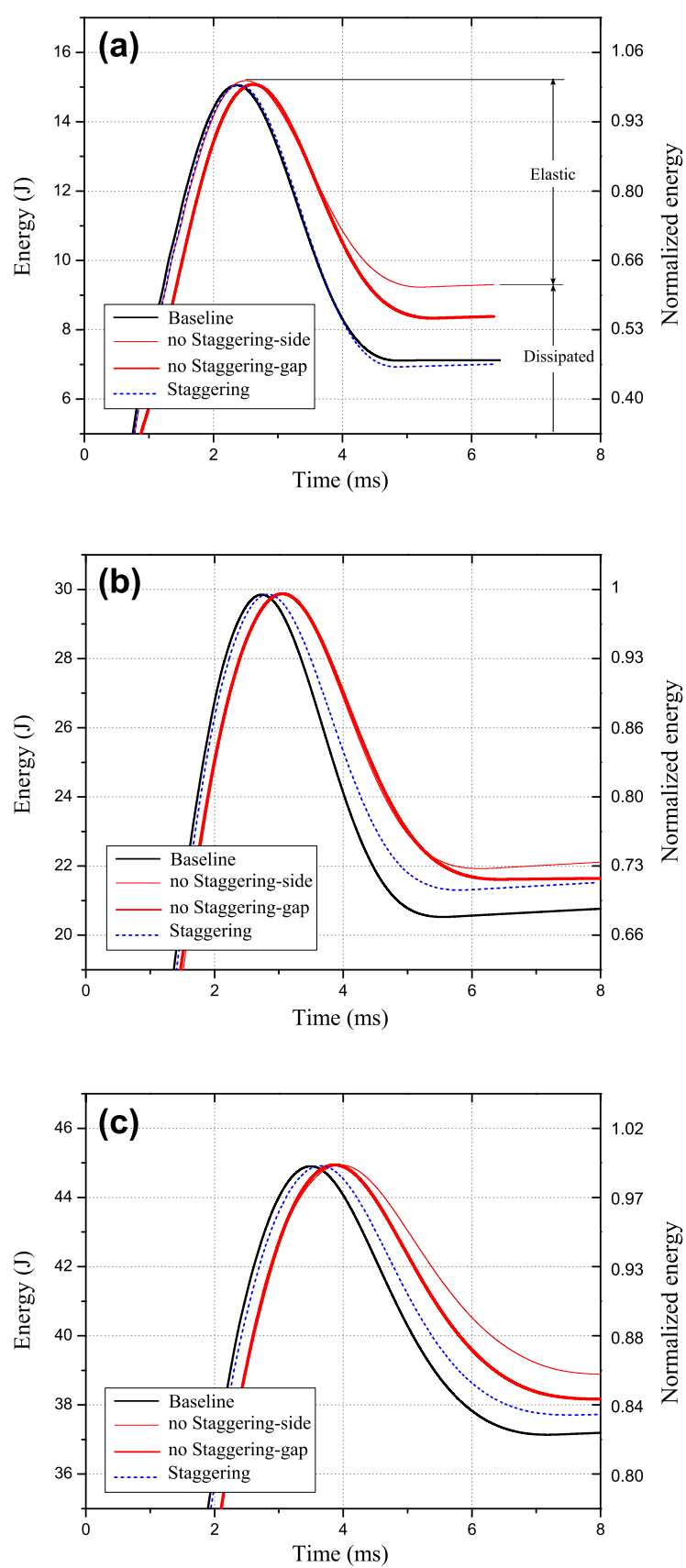

Figure 3: Evolution of the absorbed energies of configurations 'Baseline', 'no Staggering' and 'Staggering': (a) $15 \mathrm{~J}$, (b) $30 \mathrm{~J}$ and (c) $45 \mathrm{~J}$. The elastic energy and the energy dissipated are represented in the plot (a).

applied, the dissipated energy values are close to the baseline configuration in comparison to the other configurations. Therefore, results indicate that the influence of the gap defects in the dissipated energies is more representative in low values of the impact energy. For higher 
energy levels, the gaps lose influence, and this is probably indicative of failure mechanisms occurring at higher energies, such as fiber failure, are not so influenced by the resin-rich gaps defect. This behavior for the lower impact energy is clearly observed in the normalized dissipated energies $E_{\mathrm{a}}$, depicted in Fig. 6a. In these diagrams the results of all the impacted specimens are included. As expected, the dissipated energy increases when increasing the impact energy. Lower dispersion of the absorbed energy values is observed between the configurations analyzed at higher impact energies.

The projected delamination areas as identified by C-Scan inspections are shown in Fig. 4. The shape of the projected delamination area for the configuration with staggering and baseline configuration subjected to $15 \mathrm{~J}$ impact is almost circular. In comparison, for the configuration without staggering, the shape follows a more irregular pattern, influenced by the orientation of the gap zones. However, for high values of the impact energy, the shape of the areas does not present significant differences. With the C-Scan, the location of the 'tow-drop effect' (or 'gap defect') is clearly observed. For impact energy values of $30 \mathrm{~J}$, a large delamination is observed at the interface furthest away from the impact point with a dominant propagation angle of $45^{\circ}$. The delamination axis is more aligned with the ply angles than with the defect angles.

A comparison of the ply splitting on the non-impacted face is shown in Fig. 5. In spite of having similar delamination areas, more splitting is observed in the no staggering configuration.

A graphical summary of the delamination area in function of the impact energy is represented in Fig. 6b. Here, the delamination area, $A_{\mathrm{d}}$, is normalized by the unsupported area during the impact $(125 \mathrm{~mm} \times 75 \mathrm{~mm})$. Linear interpolation trends are also represented in the same graphs. The positive slope for all configurations is mainly due to the increasing delamination of the back face of the specimen. It is observed that the distribution of $A_{\mathrm{d}}$ is similar for the baseline and for the staggered configurations. Besides the slight differences observed, in general the effect of the gap defect has little influence on the normalized delamination areas $A_{\mathrm{d}}$. Nonetheless, a more irregular trend is observed for the configuration without staggering. It could be reasoned that, at lower energies fiber gaps trigger relatively larger damage, whilst at higher energies, gaps tend to concentrate damage in a narrower 
Baseline
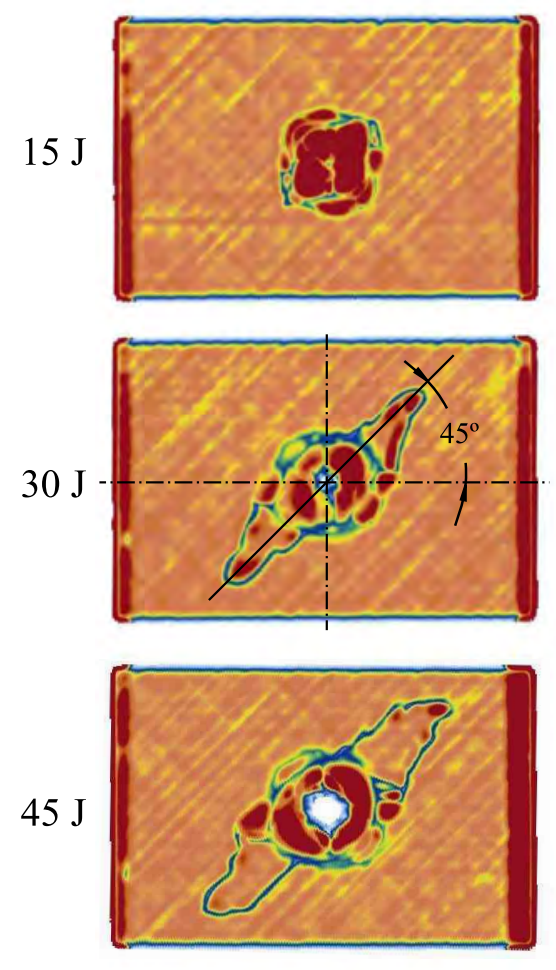

$0 \%$ gap coverage
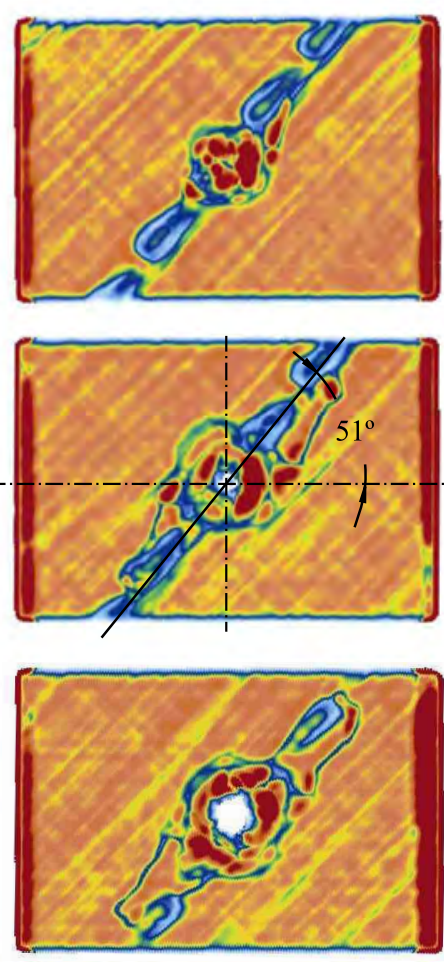

$0 \%$ gap coverage with (Staggering)
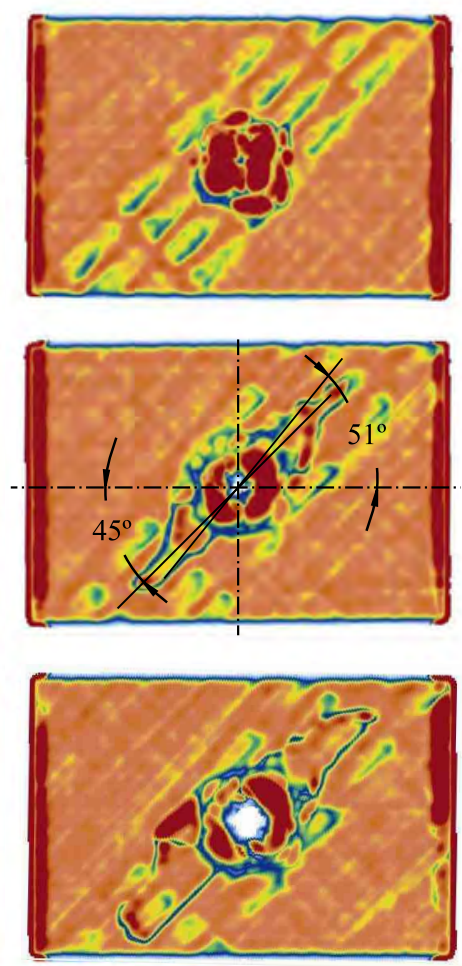

Figure 4: C-scan inspection for the laminates.

gap.

\subsection{Compression after impact results}

The contour plots of the longitudinal $\varepsilon_{y y}$ and shear $\varepsilon_{x y}$ strain for the three configurations impacted at $15 \mathrm{~J}$ are compared in Fig. 7. In the strain field analyses, the differences between each configuration are observed. It is also possible to observe the strain differences due to the mismatch angle discontinuities in the inner layers for the configurations without staggering and for the configuration with the staggered gaps - the discontinuity is identified by a dashed line in Fig 7. As expected, the region with higher strain values is the zone with layers with the fiber angle orientation of $51^{\circ}$.

The results obtained with the compression after impact test on all configurations are compared in Fig. 8 in order to assess the effect of the impact damage on the residual 


\section{Baseline}
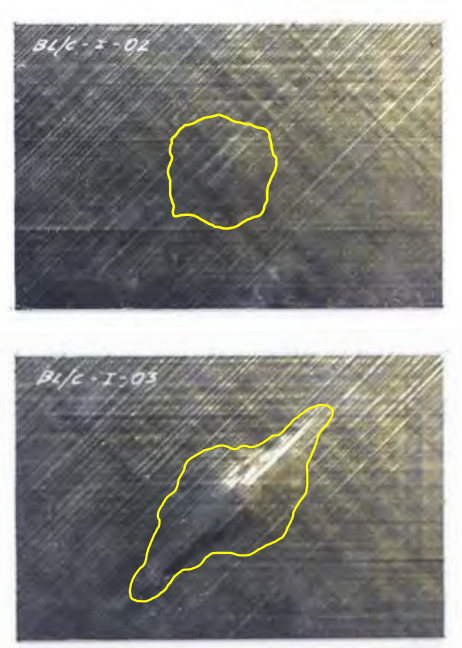

$30 \mathrm{~J}$

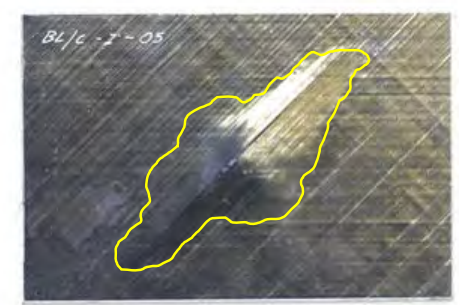

no Staggering
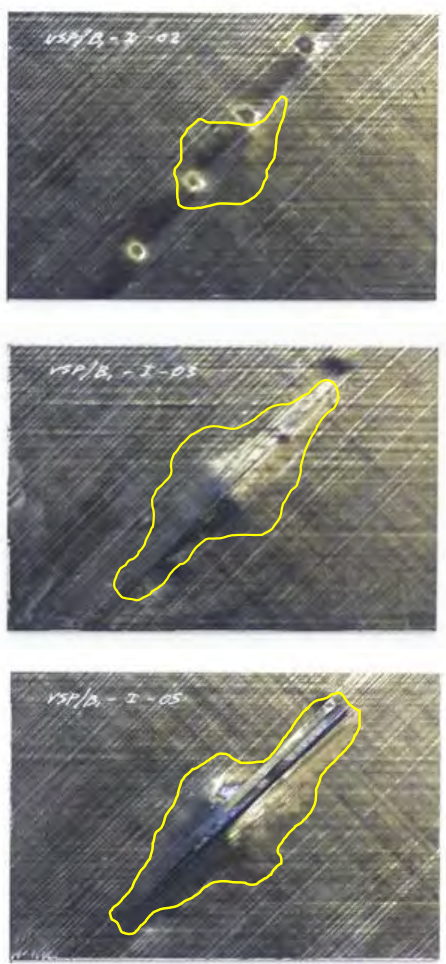

Staggering
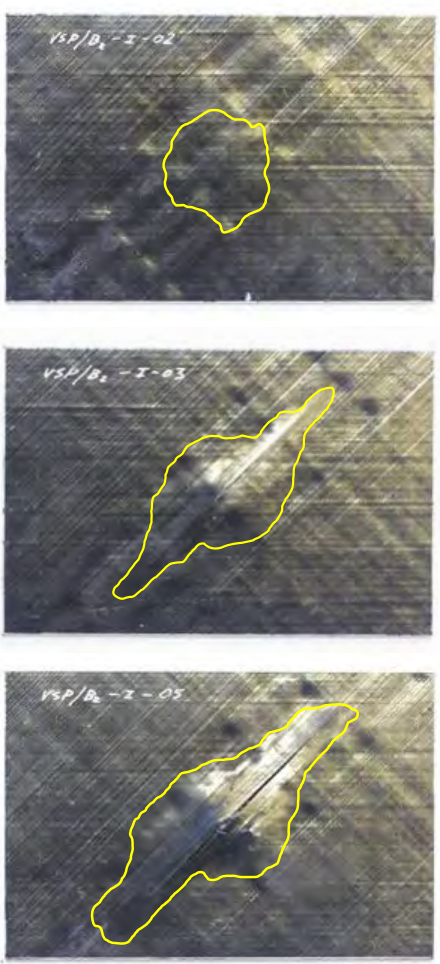

Figure 5: Visual inspection of non-impacted face for the configuration tested.
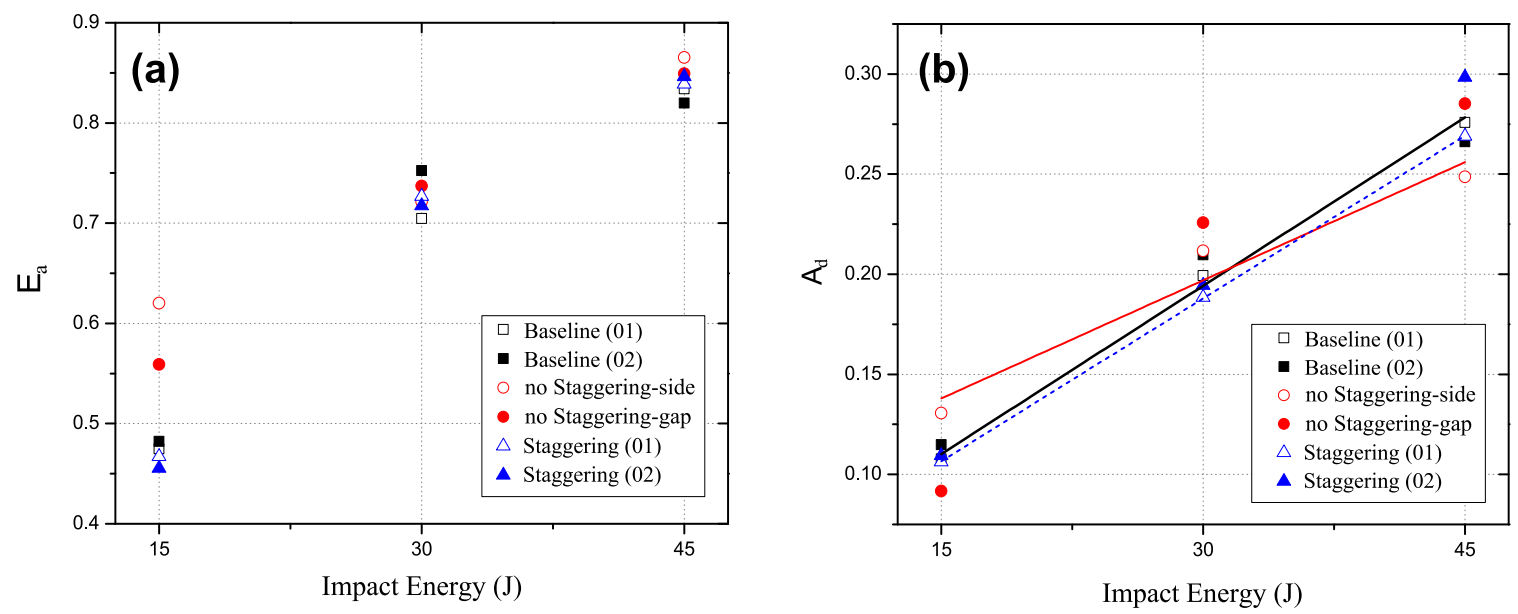

Figure 6: (a) Dissipated energy normalized, and (b) normalized projected area according to the impact energy of configurations 'Baseline', 'no Staggering' and 'Staggering'. 


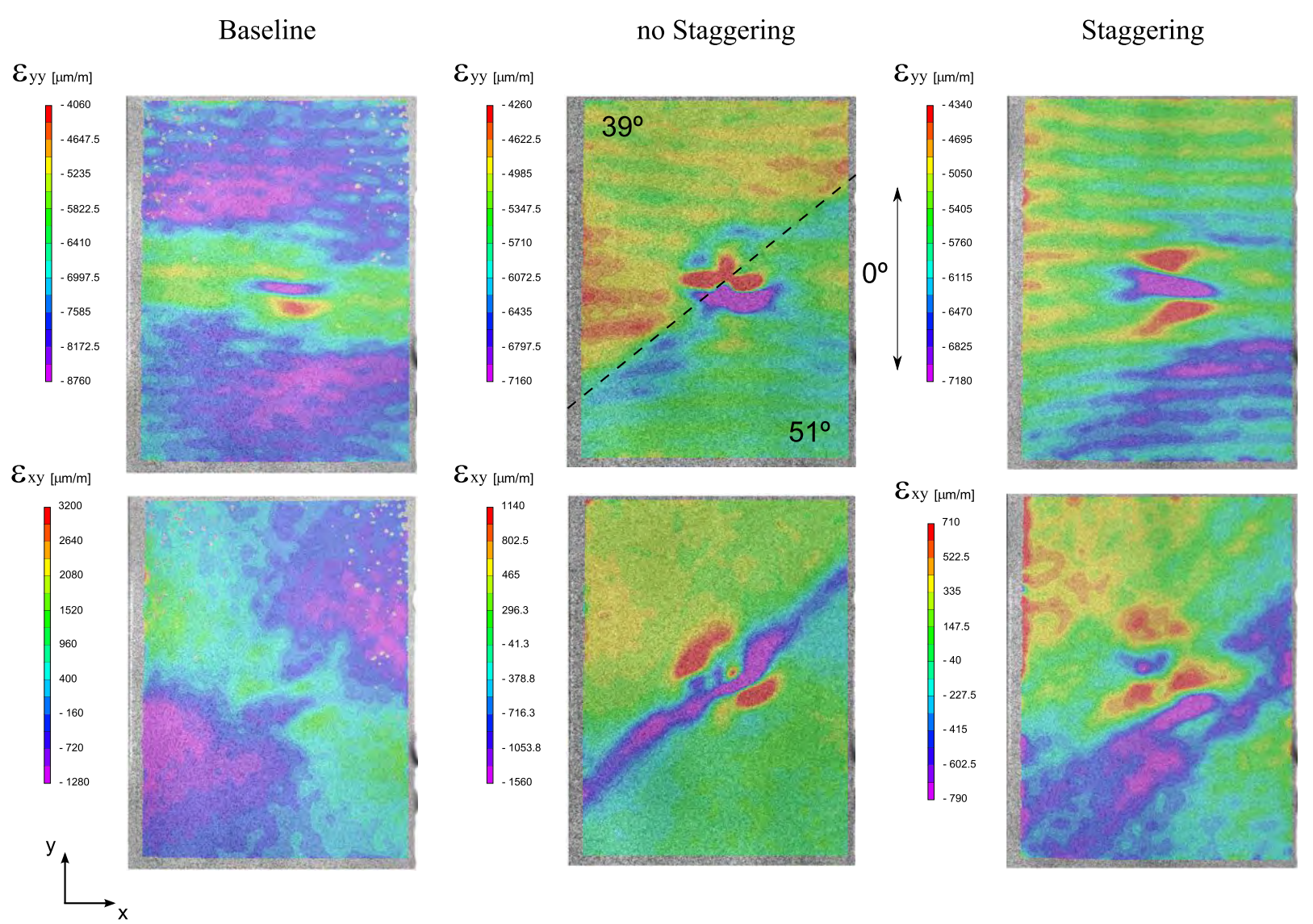

Figure 7: DIC contours of longitudinal field strain $\varepsilon_{y y}$, shear field strain $\varepsilon_{x y}$ and out-of-plane displacement $w$ for the configurations: 'Baseline', 'no Staggering' and 'Staggering' at impact energy of 15 J and compression load value of $81.1 \mathrm{kN}, 64.0 \mathrm{kN}$ and $68.0 \mathrm{kN}$, respectively.

compressive strength $\left(\sigma_{\mathrm{c}}\right)$. As expected, the maximum residual compressive load values for all laminate configurations decreases for all laminates when the impact energy increases. All configurations present a similar behavior of the residual compressive loads, although for the particular case of the specimen 'no Staggering-gap' and for all impact energy values, a slightly higher reduction of the maximum compressive load is observed, as well as of the stiffness reduction. Fig 8 also includes the results for two non-impacted baseline specimens. The numerical values for the residual compressive strengths are shown in Table 2. Akin to the impact results, the greatest dispersion of the residual value occurs for the lowest value of the impact energy $(15 \mathrm{~J})$. The differences in the residual strength between the different configurations at each impact energy level are relatively small. 
Table 2: Residual compressive strengths $\left(\sigma_{\mathrm{c}}\right)$ in MPa.

\begin{tabular}{ccccccc}
\hline & \multicolumn{5}{c}{ Configurations } \\
\cline { 2 - 7 } & \multicolumn{2}{c}{ Baseline } & \multicolumn{2}{c}{ no Staggering } & \multicolumn{2}{c}{ Staggering } \\
Impact energy $(\mathrm{J})$ & $(01)$ & $(02)$ & $($ side) & (gap) & $(01)$ & $(02)$ \\
\hline 0 & 289.2 & 308.7 & $\mathrm{n} / \mathrm{a}$ & $\mathrm{n} / \mathrm{a}$ & $\mathrm{n} / \mathrm{a}$ & $\mathrm{n} / \mathrm{a}$ \\
15 & 207.0 & 205.6 & 184.4 & 201.4 & 194.0 & 189.9 \\
30 & 165.9 & 162.3 & 152.3 & $\mathrm{n} / \mathrm{a}$ & 156.5 & 157.7 \\
45 & 143.9 & 142.4 & 139.9 & 134.2 & 140.8 & 142.8 \\
\hline
\end{tabular}

It can be concluded that the gaps do not attract such a large amount of damage as in conventionally laminates so as to significantly reduce the residual strength of the laminates. Therefore, the influence of staggering is negligible. This was also observed in the results obtained for variable stiffness specimens with gaps in previous experimental tests under an in-plane loading condition for notched specimens with open-hole [25].
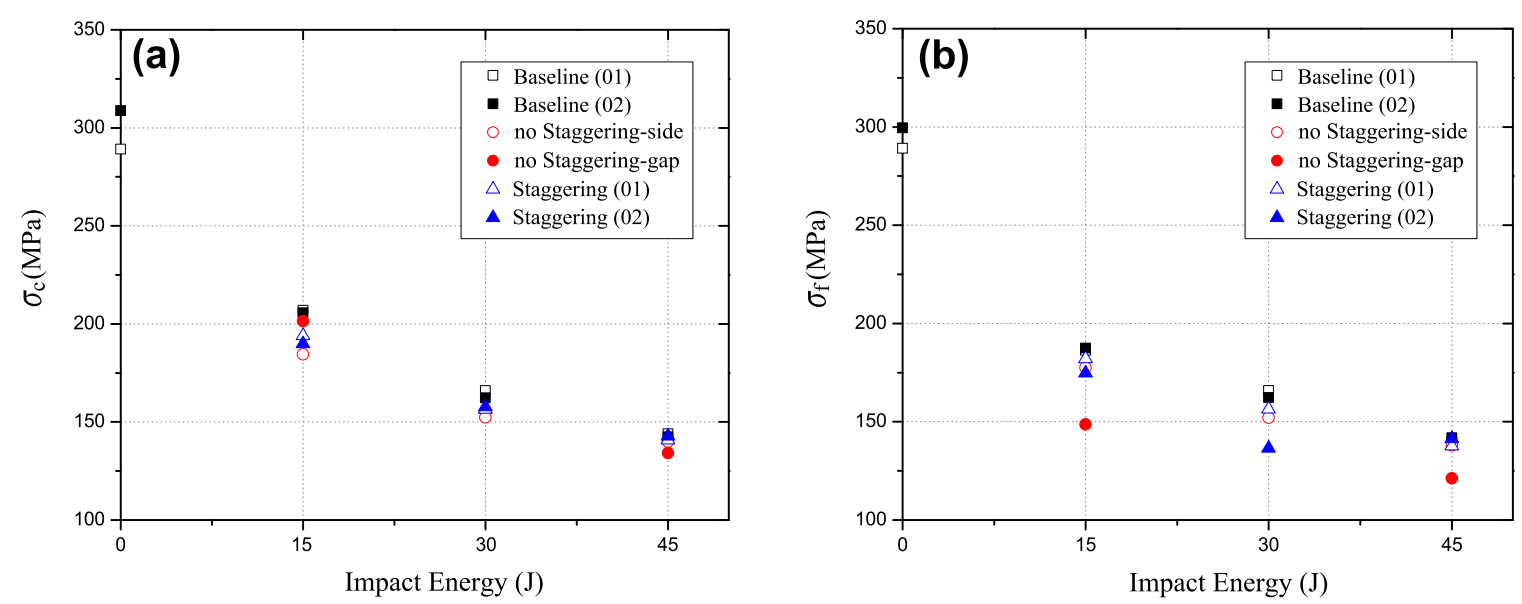

Figure 8: (a) Residual compressive strength $\left(\sigma_{\mathrm{c}}\right)$, versus the impact energy for the configurations: 'Baseline', 'no Staggering' and 'Staggering'. (b) Damage onset stress $\left(\sigma_{\mathrm{f}}\right)$.

In addition, the local buckling onset stress $\left(\sigma_{\mathrm{f}}\right)$ is plotted in Fig $8 \mathrm{~b}$. The analysis of $\left(\sigma_{\mathrm{f}}\right)$, reveals that for small impact energies their values are significantly lower that the residual strength $\left(\sigma_{\mathrm{c}}\right)$. Whereas, for higher energies the values of local buckling onset and values of ultimate stress are much more similar. 


\section{Conclusions}

The main goal of this work was to study the influence of gap defects on the damage resistance and damage tolerance of VSP under low-velocity impacts. Two configurations with tow-drop defects and $0 \%$ gap-coverage have been designed and tested. The difference between them consists in the use of ply staggering. Both configurations have been compared with a traditional straight fiber laminate.

The study of the damage resistance, with three levels of low velocity impact energy, indicates that the influence of the gap defects is relevant only under small impact energy values, and is more relevant on impact resistance than on impact damage tolerances. The damage tolerance, represented by the residual compressive strength after impact, does not present significant differences. This indicates that the strength reduction is driven mainly by the damage caused through the impact, rather than by manufacturing-induced defects. However, in order to confirm these assertions, further tests at lower impact energies would be necessary.

\section{Acknowledgements}

The authors acknowledge the financial support of the Ministerio de Economía y Competitividad of Spain under the project MAT2009-07918. The first author would like to thank the Generalitat de Catalunya for the FI pre-doctorate Grant 2010FI_B00658. The third author gratefully acknowledges the funding from the Portuguese Foundation for Science and Technology (FCT) through the project PTDC/EME-TME/111004/2009. The authors also thank Dr. Engineer Martin Nagelsmit of National Aerospace Laboratory for his assistance in the manufacturing process of the non-conventional laminates.

\section{References}

[1] Lukaszewicz D, Ward C, Potter K. The engineering aspects of automated prepreg layup: history, present and future. Composites Part B: Engineering 2012;43:997-1009.

[2] Sebaey TA, González EV, Lopes CS, N. B, J. C. Damage resistance and damage 
tolerance of dispersed CFRP laminates: Design and optimization. Composite Structures 2013;95:569-76.

[3] Gürdal Z, Tatting BF, Wu KC. Tow-placement technology and fabrication issues for laminated composite structures. In: Proceedings of the AIAA/ASME/ASCE/AHS/ASC Structures, 46th Structural Dynamics \& Materials Conference. 2005,.

[4] Gürdal Z, Olmedo R. In-plane response of laminates with spatially varying fiber orientations - variable stiffness concept. AIAA J 1993;31(4):751-8.

[5] Gürdal Z, Tatting BF, Wu KC. Variable stiffness panels: Effects of stiffness variation on the in-plane and buckling responses. Composites Part A: Applied Science and Manufacturing 2008;39:911-22.

[6] Lopes CS, Gürdal Z, Camanho P. Variable-stiffness composite panels: Buckling and first-ply failure improvements over straight-fibre laminates. Computers and Structures 2008;86:897-907.

[7] Nagendra S, Gürdal Z, T. HR. Buckling and failure characteristics of compression-loaded stiffened composite panels with a hole. Composite Structures 1994;28:1-17.

[8] Lopes CS, Gürdal Z, Camanho PP. Tailoring for strength of composite steered-fibre panels with cutouts. Composites Part A: Applied Science and Manufacturing 2010;41:176067.

[9] Tatting BF, Gurdal Z. Design and manufacture of elastically tailored tow placed plates. Tech. Rep. NASA/CR-2002-211919; NASA; 2002.

[10] Jegley DC, Tatting BF, Gürdal Z. Tow-steered panels with holes subjected to compression or shear loading. In: Proceedings of the 46th AIAA/ASME/AHS/ASC Structures, Structural Dynamics and Materials. 2005,.

[11] Blom AW, Mostafa , Abdalla M, Gürdal Z. Optimization of course locations in fiberplaced panels for general fiber angle distributions. Composites Science and Technology 2010;70:564-70. 
[12] Duvaut G, Terrel G, F. L, Verijenko VE. Optimization of fiber reinforced composites. Composite Structures 2000;48:83-9.

[13] Khani A, IJsselmuiden ST, Abdalla MM, Gürdal Z. Design of variable stiffness panels for maximum strength using lamination parameters. Composites Part B: Engineering 2011;42:546-52.

[14] Setoodeh S, Abdalla MM, IJsselmuiden ST, Gürdal Z. Design of variable-stiffness composite panels for maximum buckling load. Composite Structures 2009;87:109-17.

[15] Nik MA, Fayazbakhsh K, Pasini D, Lessard L. Surrogate-based multi-objective optimization of a composite laminate with curvilinear fibers. Composite Structures 2012;94:2306-13.

[16] Blom AW, Lopes CS, Kromwijk PJ, Gürdal Z, Camanho PP. A theoretical model to study the influence of tow-drop areas on the stiffness and strength of variable-stiffness laminates. Composite Materials 2009;43:403-25.

[17] Nik MA, Fayazbakhsh K, Pasini D, Lessard L. Optimization of variable stiffness composites with embedded defects induced by automated fiber placement. Composite Structures 2014;107:160-6.

[18] Falcó O, Mayugo JA, Lopes CS, Gascons N, Turon A, Costa J. Variable-stiffness composite panels: As-manufactured modeling and its influence on the failure behavior. Composites Part B: Engineering 2014;56:660-9.

[19] Lopes CS. Damage and failure of non-conventional composite laminates. Ph.D. thesis; Delft University of Technology; 2009.

[20] Kim BC, Potter K, Weaver PM. Continuous tow shearing for manufacturing variable angle tow composites. Composites Part A: Applied Science and Manufacturing 2012;43:1347-56.

[21] Sawicki Adan J, Minguet PJ. The effect of intraply overlaps and gaps upon the compression strength of composite laminates. In: Thirty-ninth AIAA structural, dynamics, 
material conferences, Structural Dynamics and Materials Conference. Long Beach, CA; 1998, p. $744-54$.

[22] Turoski LE. Effects of manufacturing defects on the strength of toughened carbon/epoxy prepeg composites. Master's thesis; Montana State University, Mechanical Engineering, Bozeman; 2000.

[23] Nicklaus CK. Open hole compressive behavior of laminates with converging gap defects. Master's thesis; Department of Mechanical Engineering, The University of Utah; 2011.

[24] Croft K, Lessard L, Pasini D, Hojjati M, Chen J, Yousefpour A. Experimental study of the effect of automated fiber placement induced defects on performance of composite laminates. Composites: Part A: Applied Science and Manufacturing 2011;42:484-91.

[25] Falcó O, Mayugo JA, Lopes CS, Gascons N, Costa J. Variable-stiffness composite panels: Defect tolerance under in-plane tensile loading. Composites Part A: Applied Science and Manufacturing, Submitted Nov 2013;

[26] Sebaey T, González E, Lopes C, Blanco N, Costa J. Damage resistance and damage tolerance of dispersed CFRP laminates: The bending stiffness effect. Composite Structures 2013;106:30-2.

[27] Sebaey T, González E, Lopes C, Blanco N, Costa J. Damage resistance and damage tolerance of dispersed CFRP laminates: Effect of ply clustering. Composite Structures 2013;106:96-103.

[28] Sebaey T, González E, Lopes C, Blanco N, Maimí P, Costa J. Damage resistance and damage tolerance of dispersed CFRP laminates: Effect of the mismatch angle between plies. Composite Structures 2013;101:255-64.

[29] González E, Maimí P, Camanho P, Lopes C, Blanco N. Effects of ply clustering in laminated composite plates under low-velocity impact loading. Composites Science and Technology 2011;71:805-17. 
[30] Dang TD, Hallett SR. A numerical study on impact and compression after impact behaviour of variable angle tow laminates. Composite Structures 2013;96:194-206.

[31] Rhead AT, Dodwell TJ, Butler R. The effect of tow gaps on compression after impact strength of robotically laminated structures. CMC: Computers, Materials \& Continua 2013;35:1-16.

[32] ASTM. Standard test method for measuring the damage resistance of a fiber-reinforced polymer matrix composite to a drop-weight impact event. Tech. Rep.; American Society for Testing and Materials (ASTM); West Conshohocken, PA, USA; 2012. ASTM D 7136/D 7136M-12.

[33] ASTM. Standard test method for compressive residual strength properties of damage polymer matrix composites plates. Tech. Rep.; American Society for Testing and Materials (ASTM); West Conshohocken, PA, USA; 2012. ASTM D 7137/D 71376M-12. 